\title{
Analysis of Deformation Characteristics of Long-Short Pile Composite Foundation in Salt Lake Area, Iran
}

\author{
Wei Liu $\mathbb{D}^{1,},{ }^{1,2}$ Xiaohua Yang $\left(\mathbb{D},{ }^{1}\right.$ Shasha Zhang $\left(\mathbb{D},{ }^{1}\right.$ Xiangxin Kong, ${ }^{1}$ and Weizhi Chen ${ }^{3}$ \\ ${ }^{1}$ School of Highway, Chang'an University, Xi'an 710064, China \\ ${ }^{2}$ Construction Engineering Department, Taiyuan University, Taiyuan 030009, China \\ ${ }^{3}$ China Railway Eryuan Engineering Group Co. Ltd., Chengdu 610031, China
}

Correspondence should be addressed to Xiaohua Yang; xiaohuay@126.com

Received 26 July 2019; Revised 25 September 2019; Accepted 3 October 2019; Published 5 December 2019

Academic Editor: Ayman S. Mosallam

Copyright (c) 2019 Wei Liu et al. This is an open access article distributed under the Creative Commons Attribution License, which permits unrestricted use, distribution, and reproduction in any medium, provided the original work is properly cited.

\begin{abstract}
To study the settlement and deformation characteristics of a long-short pile composite foundation and its influencing factors, the indoor centrifuge model test and numerical simulations were performed under the actual working conditions to treat the saline soft soil foundation in the Soltan salt lake area of Iran. Firstly, the settlement of a long-short pile composite foundation and the law of pile-soil stress ratio development with time were studied using a centrifuge model test. In addition, FLAC3D was used to simulate the test conditions, and it has been observed that the numerical and experimental results were in good agreement. Based on the numerical model, the effects of the replacement rate of long and short piles, cushion modulus, and pile length on the settlement of the composite foundation and the stress ratio of long and short piles were analyzed. The results show that the longshort pile composite foundation can effectively control settlement. Compared to the untreated foundation, the total settlement of a long-short pile composite foundation was reduced by $67 \%$, and the postconstruction settlement was reduced by $47.7 \%$. Compared to the final settlement of the composite foundation obtained using the centrifuge model test, the error range of the numerical simulation results was between $2.4 \%$ and $8 \%$. The influence of pile spacing on the settlement and stress characteristics of a longshort pile composite foundation is greater than that attributable to the arrangement of the piles. Under this geological condition, it is reasonable to choose a pile spacing of $4 d \sim 5 d$. When the long pile reaches the bearing stratum, the length of the short pile should not exceed 0.6 times the length of the long pile. The setting cushion not only reduces uneven settlement of the composite foundation but also improves the joint bearing capacity of the pile and the soil between the piles.
\end{abstract}

\section{Introduction}

The DY (Tehran to Isfahan) high-speed railway in Iran starts in Tehran and ends in Isfahan and has a total length of approximately $405 \mathrm{~km}$. Deep soft soil containing salt is widely distributed in the Soltan salt lake area where the highspeed railway passes. The geological location of the project is shown in Figure 1. The foundation in the salt lake area has the characteristics of high groundwater level, large salt content, and low bearing capacity. The variation of the environmental temperature causes the migration, accumulation, crystallization, and dissolution of water and salt in the soil, resulting in salt expansion, frost heave, and an increased risk of collapse of highway and railway foundations [1]. To avoid these problems, it is necessary to reinforce the foundation using appropriate ground treatment. For foundation reinforcement, the strength of the soil can be improved via precompression and replacement. Moreover, the pile technology can be used to reinforce the soft soil foundation to form a composite foundation that bears the load through the pile with high rigidity, in addition to the surrounding soil. This improves the bearing capacity of the foundation and controls its settlement [2]. Although composite foundation technology has been widely used in soft soil regions in China, it is being used for the first time in Iran.

In soft soil foundation treatment, Yang [3] determined that the use of piles has obvious effects on the reduction of the settlement of foundations. As such, it is widely used in construction. Lv et al. [2] used X-section cast-in-place concrete piles to reinforce soft soil foundations, which 


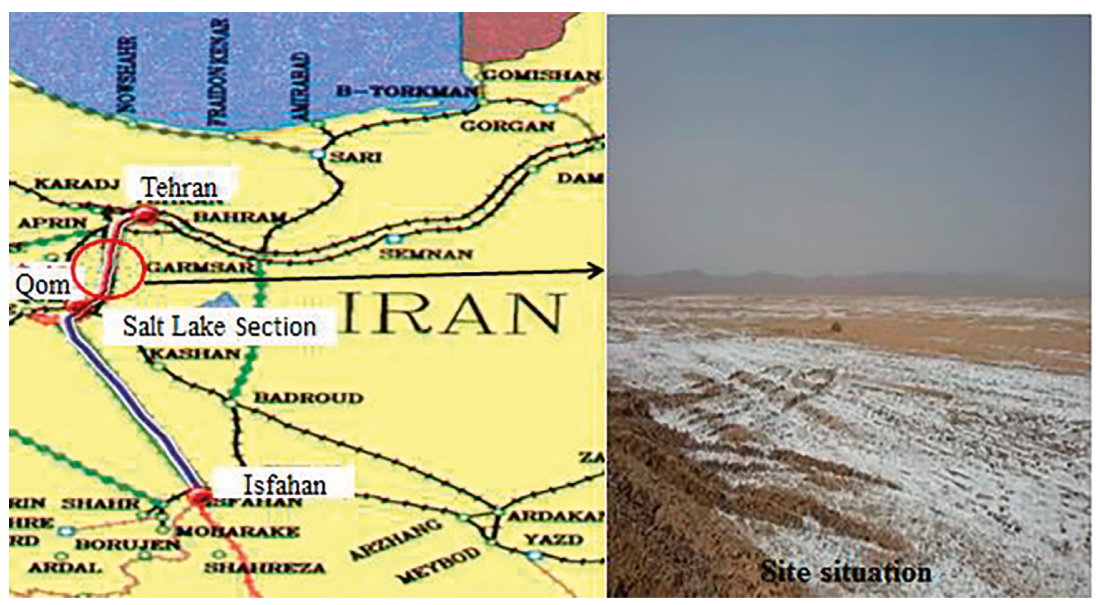

Figure 1: Geological location of the project.

significantly improved the bearing capacity of the foundation and reduced settlement. Rogers and Glendinning [4] analyzed the treatment of a soft soil foundation using lime piles and reported that it mainly relies on the reduction of the soil moisture content to densify the soil and increase its strength and rigidity to improve bearing capacity. Xu et al. [5] analyzed the problems associated with the installation of pipe piles in a soft soil foundation. Chandrasekaran et al. [6] conducted static lateral load tests of pile groups in soft soil and studied the influence of pile spacing, pile number, embedded length, and pile group structure on pile group interaction. Liu et al. [7] observed that when large-diameter cast-in situ concrete pipe piles are used to treat soft soil foundations, the construction speed increases and it is economical and effective. Some scholars have also investigated electroosmotic reinforcement of soft soil foundations [8-10]. For different saline soil foundations, many ground treatment methods have also been applied. Yue et al. [11] carried out a laboratory test on the foundation treatment of sulphate saline sandy soil by a heavy cover replacement technique and discussed the specific thickness of heavy cover replacement. Through an in situ test, Zhang et al. [12] concluded that dynamic compaction replacement has good effect in strengthening chlorine saline soil foundations. In view of saturated saline soil, dynamic consolidation and drainage stone columns have been put forward and the corresponding experimental research has been carried out $[13,14]$. Several studies have been conducted on the treatment of soft soil and saline soil foundations, and the application of ground treatment methods is relatively well established. However, there are comparatively few studies on the treatment of soft soil and saline soil foundations using long and short piles.

A long-short pile foundation is a composite foundation formed using long-short piles comprised of rigid and flexible piles. This composite foundation effectively exploits the advantages of both piles. It not only improves the participation of the soil between the piles but also effectively improves the strength of the foundation, reduces the settlement, speeds up construction, and reduces overall cost. The rigid pile is used as a long pile, which not only improves the bearing capacity of the composite foundation but also reduces its settlement. Short piles can be selected from rigid piles, semirigid piles, or flexible piles and are mainly used to improve the bearing capacity of composite foundations [15]. This is similar to the concepts of composite piled raft foundation and multielement composite foundations proposed by scholars [16-20].

Liang et al. [16] studied the mechanical behavior of composite piled raft foundation under vertical load through the finite element method and verified the reliability of test results by an engineering case. Similarly, Zheng et al. [17] investigated the behavior of composite CFG-lime pile foundations under various load distributions using finite element software. Wang et al. [18] designed and carried out a series of model tests on multielement composite foundations with different combinations of vertical reinforcement columns and piles. The results revealed multielement composite foundations (such as a combination of steel pipe pile and sand column or a combination of concrete pile and lime column) have a higher bearing capacity than the composite foundation with only sand columns with the same conditions. Through three-dimensional finite element software, Samanta and Bhowmik $[19,20]$ studied the efficacy of improving the soft soil by stone columns on the response of a piled raft foundation. Studies showed that reinforcing the shallow soft soil with stone columns can effectively improve the bearing interaction of the raft. Zhao et al. [21] discussed the mechanism of the long-short composite pile-raft foundation. Considering the influence of the cushion, the flexibility factors of the interaction were determined and a settlement calculation method for the long-short composite pile-raft foundation was proposed. Lou et al. [22] tested and analyzed the long-short pile soil arching effect based on field tests. The results showed that increasing the replacement rate of the pile can effectively increase its bearing ratio. Li et al. [23] conducted field tests and numerical simulations of longshort pile composite foundations under embankment loads. The results confirmed that when the sum of the lengths of all long and short piles is the same as the sum of the lengths of all equal-length piles, the reinforcement effect of the longshort pile composite foundation is better than that of the 
equal-length pile composite foundation, and the presence of a bearing layer is beneficial to its performance. Lin et al. [24] relied on engineering examples to analyze the causes of failures of long and short pile composite foundations based on on-site investigations, monitoring, and theoretical adjustment and proposed corresponding preventive measures. Moreover, the analysis of the bearing capacity, deformation characteristics, and influencing factors of long-short pile reinforced loess foundations has been pursued [25-28].

These studies were mainly conducted on soft soil or loess foundation without salt. Theoretical calculations, field tests, and numerical simulation methods were used to analyze the settlement and bearing capacity of long-short pile composite foundations. However, the analysis of the settlement characteristics and influencing factors of these foundations is not comprehensive and few studies have been conducted using indoor centrifuge model tests. The centrifuge model test can simulate the true size of a structure in a high centrifugal field using a small-scale model. It has the advantages of easy control of the test process, test repeatability, and easy adjustment of the characteristics of the foundation soil $[29,30]$. Furthermore, when the salt content in the soft soil is high, the selection of the pile type should consider the corrosion of the pile due to the salt, which is quite different from the conventional soft soil and loess foundation.

In this report, based on the DY high-speed railway project, the indoor centrifuge model test was conducted according to the actual conditions of the long-short pile treatment of the saline soft soil foundation in the salt lake area. The settlement characteristics of the rigid-flexible longshort pile composite foundation and the variation of the pile-soil stress ratio with time were systematically analyzed. Moreover, numerical simulations were performed using FLAC3D 5.0 finite difference software and compared with the results of centrifugal tests. After verifying the reasonableness and reliability of the numerical model, the influence ratios of the replacement ratio (the layout form and pile spacing), cushion modulus, and pile length ratio of the longshort pile composite foundation were analyzed. The results not only provide technical reference for the foundation treatment of the high-speed railway project but also expand the available knowledge on long-short pile composite foundations to facilitate their widespread application.

\section{Project Overview}

The saline soil in the Soltan salt lake region is a medium and strong saline soil. The types of salt in the soil are mainly chlorides and chlorites, followed by sulfites and sulfates. Through typical bore log of the site, the upper layer is saline soft soil and the lower layer is saline clay, in a typical geological profile of the site, as shown in Figures 2(a) and 2(b). The saline soft soil layer is grey-brown and in a soft plastic state. Part of the thin layer is in a hard-plastic state and contains a thin silt sandwich with $5-10 \%$ fine sand and low toughness. The maximum thickness of this layer is $19.6 \mathrm{~m}$. The saline clay layer is grey-brown, grey-yellow, and light-yellow in a hard-plastic local hard state containing 5-10\% fine sand. The local soil layer contains a thin layer of silt and a fine sand interlayer. The soil layer has medium toughness and high dry strength and generally has a thickness of 2-13 $\mathrm{m}$ and a partial thickness of $37 \mathrm{~m}$. The peak acceleration of the ground motion of the survey area is $0.30 \mathrm{~g}$, which is a high-intensity seismic zone. Saturated and poorly graded sands have the potential to liquefy. The groundwater in this area is deeply buried, and both soil and groundwater are highly corrosive.

Long and short piles are used for foundation treatment because of the poor geological conditions of the salt lake section and the strict requirement of allowable settlement and deformation of the high-speed railway. The corrosiveness of saline soil is considered in the selection of the pile type. Therefore, the long piles are made of precast concrete piles. The length of the piles is $22 \mathrm{~m}$, and the cross-section size is $0.45 \mathrm{~m} \times 0.45 \mathrm{~m}$. The short piles are made of gravel pile with a length of $10 \mathrm{~m}$ and a pile diameter of $0.5 \mathrm{~m}$. In addition, auxiliary measures such as cushion and geogrid are used to isolate the water-salt migration, optimize the pilesoil stress ratio, and to effectively exploit the bearing capacity of the composite foundation reinforcement. The section of on-site embankment, piles, and foundation are shown in Figure 2(c). Among them, the roadbed height is $5 \mathrm{~m}$ and the road width is $13.6 \mathrm{~m}$.

\section{Centrifuge Model Tests}

\subsection{Test Design}

3.1.1. Materials. Given the difficulty in sampling undisturbed soil, the remolded soil was manually prepared in this experiment. According to the geological conditions of the site, the test foundation soil was divided into two layers. The main physical and mechanical indexes are shown in Table 1 . To ensure that the strength of the foundation soil used in the centrifuge model test was the same as that of the in situ soil, numerous exploratory tests were performed. The results indicated that the strength of the simulated soil was consistent with that of the natural soil after centrifuge consolidation for 3 hours. Loess was selected as the embankment filling material and the corresponding embankment model was made by controlling the gravity density of the soil.

To accurately simulate the concrete material, 6061 grade of aluminum alloy was used to simulate a precast concrete square pile. Its tensile yield strength, elastic modulus, Poisson's ratio, and density are 55.2 MPa, 68.9 GPa, 0.3 , and $2.7 \mathrm{~g} / \mathrm{cm}^{3}$, respectively. Sand with different particle sizes was used as the simulation material for the gravel piles, and the particle sizes were determined by the model similarity ratio and test conditions. The degree of compactness was controlled by the quality of the sand filling.

3.1.2. Test Apparatus and Instrument. The TLJ-3 Geotechnical Centrifuge of Chang'an University was used in the experiment. Its main performance indicators are the effective radius of the centrifuge of $2 \mathrm{~m}$, the volume of the experimental model box of $700 \mathrm{~mm} \times 360 \mathrm{~mm} \times 500 \mathrm{~mm}$, and the centrifuge capacity of $60 \mathrm{gt}$. A KTR11-25 spring self- 


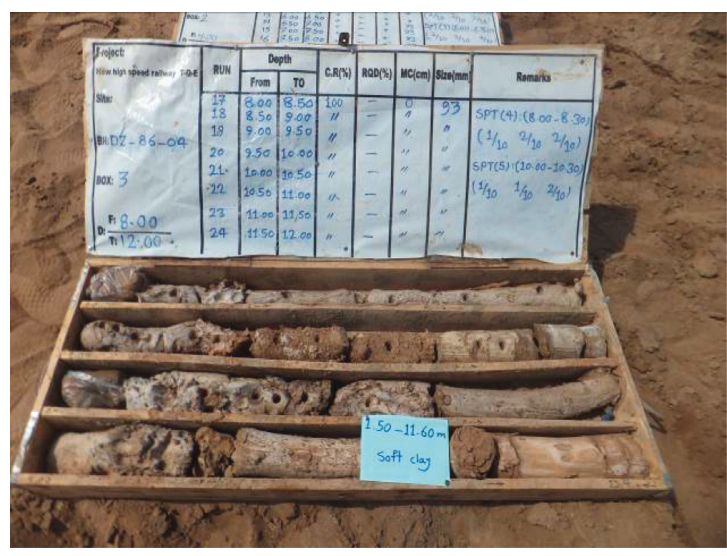

(a)

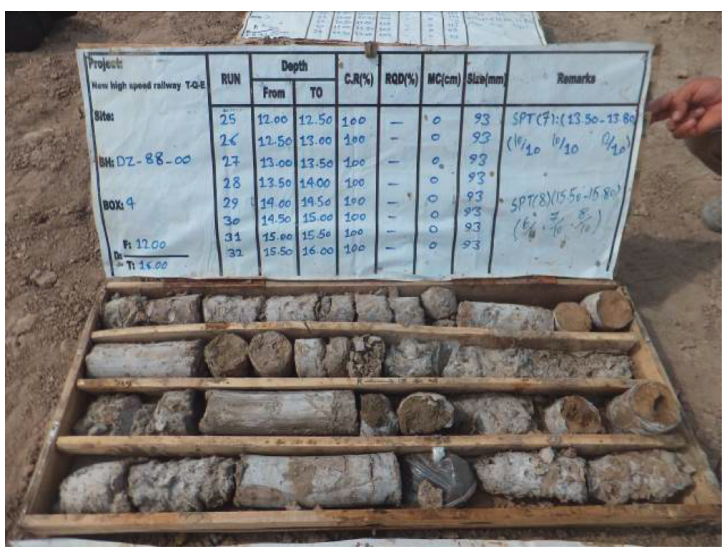

(b)

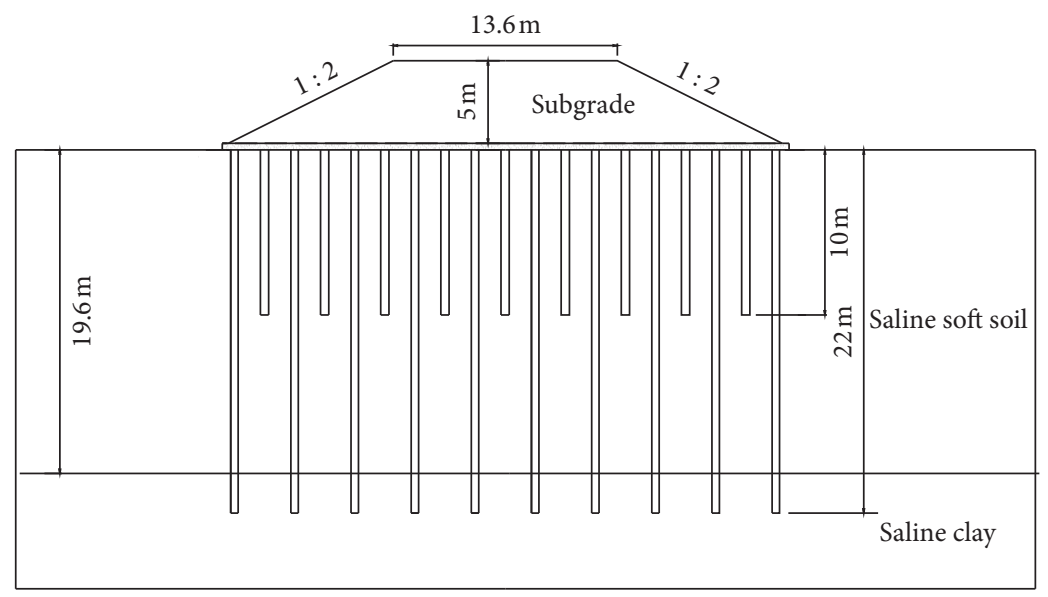

(c)

Figure 2: Typical bore diagram on-site and schematic section of proposed foundation schemes. (a) Saline soft soil. (b) Saline clay. (c) Schematic section of the proposed foundation schemes.

TABLE 1: Main physical and mechanical indexes of model foundation soil.

\begin{tabular}{lcccc}
\hline Name & Moisture content $(\%)$ & Density $\left(\mathrm{g} / \mathrm{cm}^{3}\right)$ & Cohesion $(\mathrm{kPa})$ & Internal friction angle $\left({ }^{\circ}\right)$ \\
\hline Saline soft soil & 24.2 & 1.61 & 11.5 & 14.4 \\
Saline clay & 8.6 & 1.78 & 20.1 & 23.6 \\
\hline
\end{tabular}

resetting linear displacement sensor with a precision of $0.01 \mathrm{~mm}$ was installed in the experiment, and it was used with a self-made settlement mark. In addition, a TY1005 micro earth pressure sensor was installed with a measurement range of $0-500 \mathrm{kPa}$, precision of $\pm 1 \% \mathrm{FS}$, and the diameter of circular induction surface of $8 \mathrm{~mm}$, as shown in Figure 3.

3.1.3. Test Procedure. According to the similarity theory of the centrifuge model test, the similarity ratio $n=80$ is determined in this test considering factors such as the size of the model, the feasibility of the test process, and test effects. The physical quantities' similarity ratios between the centrifuge and prototype scale are shown in Table 2 . In addition, half of the subgrade section was selected for centrifuge model testing. In this way, a centrifugal inertial force of $80 \mathrm{~g}$ was applied to the model via a centrifuge with high-speed rotation. The loss of self-weight stress caused by reducing the size of the model to $1 / 80$ of the original size can be compensated, and the model can achieve the same stress level as the original model. Thus, the properties of the original geotechnical structures can be reproduced in the model [31].

To avoid the situation hereby the number of piles used is too large and the diameter of the piles is too small to place sensors on the surface of the piles, the diameter and spacing of the piles are adjusted under the condition that the replacement rate of the composite foundation is the same, and the parameters of the model pile are finally determined. The length of the long pile is $275 \mathrm{~mm}$, and the cross section size of the pile is $8 \mathrm{~mm}$. The length and diameter of the short pile are $125 \mathrm{~mm}$ and $9 \mathrm{~mm}$, respectively. The piles are spaced $32 \mathrm{~mm}$ apart and are arranged in a square pattern. The specific test model and instrument layout are shown in Figure 4. To 


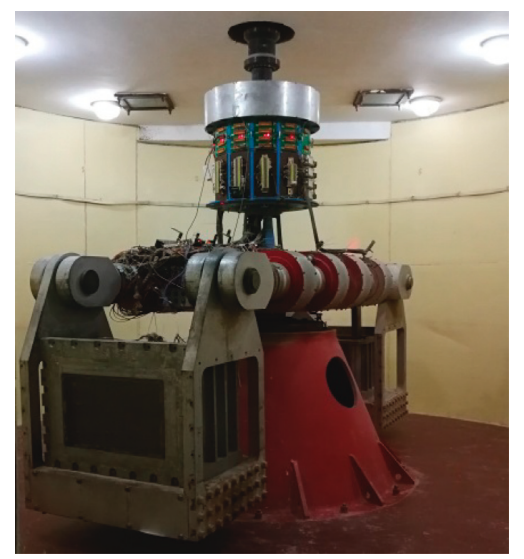

(a)

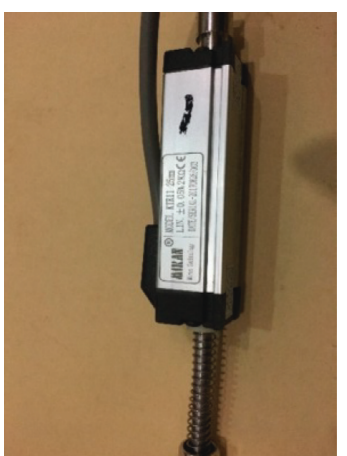

(b)

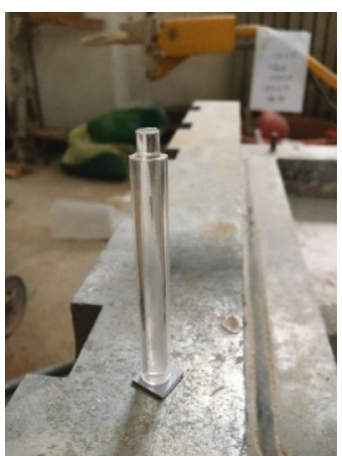

(c)

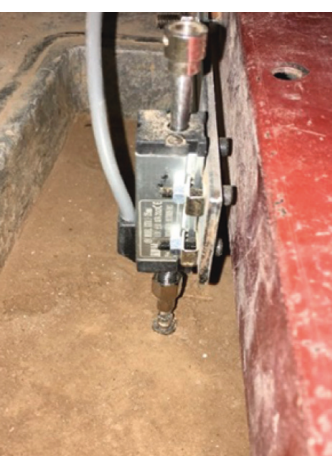

(d)

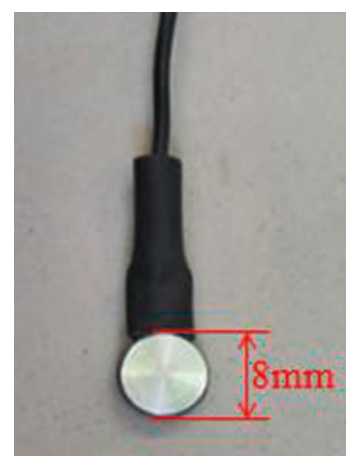

(e)

Figure 3: Testing equipment and instruments. (a) Test centrifuge. (b) Displacement sensor. (c) Settlement mark. (d) Combination diagram. (e) Pressure sensor.

TABLE 2: The physical quantities' similarity ratios used in centrifuge model tests.

\begin{tabular}{lcccccccc}
\hline Physical quantity & Model size & Density & Settlement & Strain & Stress & Force & Gravity acceleration & Consolidation time \\
\hline Similar ratio (prototype/model) & $n$ & 1 & $n$ & 1 & 1 & $n^{2}$ & $1 / n$ & $n^{2}$ \\
\hline
\end{tabular}

facilitate comparative analysis, a control group is set up which differs from the test group where no treatment was performed on the foundation. According to JGJ79-2012 [32], the diameter of gravel pile filler ranges from $20 \mathrm{~mm}$ to $150 \mathrm{~mm}$. Considering the model similarity ratio and the test conditions, sand with particle size of $0.5 \mathrm{~mm} \sim 2 \mathrm{~mm}$ was used as the simulation material for the gravel piles.

In the test, the foundation model is made first. According to the volume converted to soil weight, the prepared foundation soil is weighed and added to the model box in several layers. Usually, soil with a thickness of $4-5 \mathrm{~cm}$ was filled in each layer until all the soil samples were filled. Given that there are different types of foundation soils, it is necessary to sort and fill them in order. The upper portion is filled after the lower layer is completed.

In piling, to verify the quality of the gravel piles, square piles were first driven into the foundation and then gravel piles were made. The concrete process of forming gravel pile was as follows: Firstly, the seamless thin-walled steel pipe was pressed into the specified depth of the foundation soil. The soil in the steel pipe was taken out with spiral soil collector, and the hole was carefully cleared. Then, the steel pipe was slowly rotated and pulled out to avoid damage to the hole wall. Finally, a certain amount of sand was penetrated into the hole with a funnel and compacted layer by layer. After all the model piles were driven into the foundation, the cushion and geogrid were laid. The earth pressure sensor and settlement marks were installed in preset positions then. Finally, the embankment was filled in layers. The foundation of the control group was not treated, and the embankment was directly filled on the foundation and compacted layer by layer. The physical structure of the model is shown in Figure 5.

According to the time similarity ratio, the running time of the centrifuge model test was converted, and the acceleration process was designed. Acceleration can be applied in three categories: preloading of the foundation soil model, simulation of different embankment filling heights $(2 \mathrm{~m}$, $4 \mathrm{~m}$, and $5 \mathrm{~m}$ ), and postconstruction time. The total running time of the centrifuge was $8.09 \mathrm{~h}$. To ensure close contact between the sensor and the measuring object and the model parts, the centrifuge was energized for 10 minutes and then accelerated to $10 \mathrm{~g}$ to start the formal testing. In addition, the 


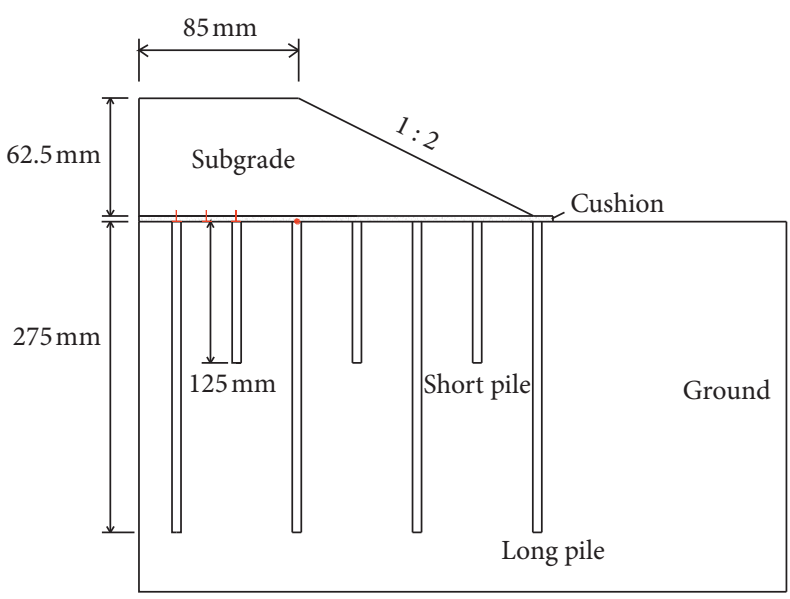

(a)

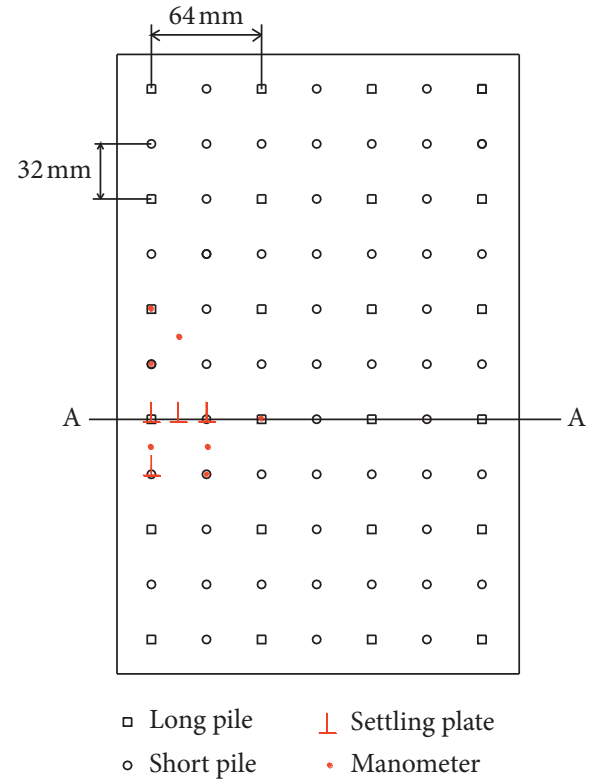

(b)

Figure 4: The specific test model and instrument layout. (a) A-A sectional view. (b) Top view.

data acquisition system was initiated to record the sensor data. The specific running time is shown in Figure 6.

\subsection{Results and Discussion}

3.2.1. Settlement Law. Figures 7 and 8 present graphs showing the change of the accumulated settlement of the foundation with time in the test and the control groups. The settlement in the figure was converted to the actual settlement value for easy analysis.

It is evident from Figure 7 that the settlement of untreated foundation and long-short pile composite foundation increases with the increase in the filling height in 90 days of simulated embankment filling. The settlement of the foundations gradually stabilized after about 1000 days. The maximum cumulative settlement of untreated foundation was $256.7 \mathrm{~mm}$, and the postconstruction settlement was $86.4 \mathrm{~mm}$, which exceeds $72.8 \%$ of the design standard $(50 \mathrm{~mm})$. In actual construction, the embankment filling speed may be faster than the experimental design speed. In addition, the foundation soil produces long-term consolidation deformation, so the postconstruction settlement increases further. It is also evident based on the figure that the settlement generated during the embankment filling process accounts for a large proportion of the cumulative total settlement. In particular, the settlement of the untreated foundation after the completion of embankment was $170.3 \mathrm{~mm}$, accounting to $66.3 \%$ of the total settlement. For the long-short pile composite foundation, after the embankment was completed, the cumulative settlement at the top of the long pile, the top of the short pile, and the soil between the piles was $25.4 \mathrm{~mm}, 37.2 \mathrm{~mm}$, and $43.4 \mathrm{~mm}$, respectively. These accounted for $52.4 \%, 49.5 \%$, and $48.7 \%$ of the total accumulated settlement, respectively, and the corresponding postconstruction settlements were $28 \mathrm{~mm}$, $36.5 \mathrm{~mm}$, and $41.2 \mathrm{~mm}$, respectively.

It is evident from Figure 8 that the settlement of the treated foundation is significantly reduced. Compared to the untreated foundation, the total settlement of the long-short pile composite foundation was reduced by $67 \%$, and the postconstruction settlement was reduced by $47.7 \%$. The postconstruction settlement of the long-short pile composite foundation was approximately half of its total accumulated settlement. This shows that the use of long and short piles facilitates a more stable development process of foundation settlement and the proportion of postconstruction settlement is relatively large. However, the bearing capacity of the foundation increases rapidly, and consequently, the settlement of the foundation decreases because long and short piles reinforce the soil between the piles. Moreover, the gravel pile increases the drainage of the channel of the foundation soil which facilitates long-term consolidation of this soil, resulting in a relatively large proportion of postconstruction settlement.

3.2.2. Variation Law of Pile-Soil Stress Ratio. The curve of the pile-soil stress ratio of long-short pile composite foundation varying with time is shown in Figure 9. With the increase of the embankment filling height, the pile-soil stress ratio of each pile increases continuously. After the embankment is completed, the pile-soil stress ratio peaks and then decreases slightly. The variation ratio of the pile-soil stress ratio gradually decreases with time, and the composite foundation tends to be more stable. This is because the compressibility of the pile is less than the compressibility of the soil between the piles. In the process of embankment filling, the settlement of the soil between the piles is larger than that of the pile top. As the overlying load on the foundation increases, the pressure on the pile top increases and gradually reaches its peak value. When 


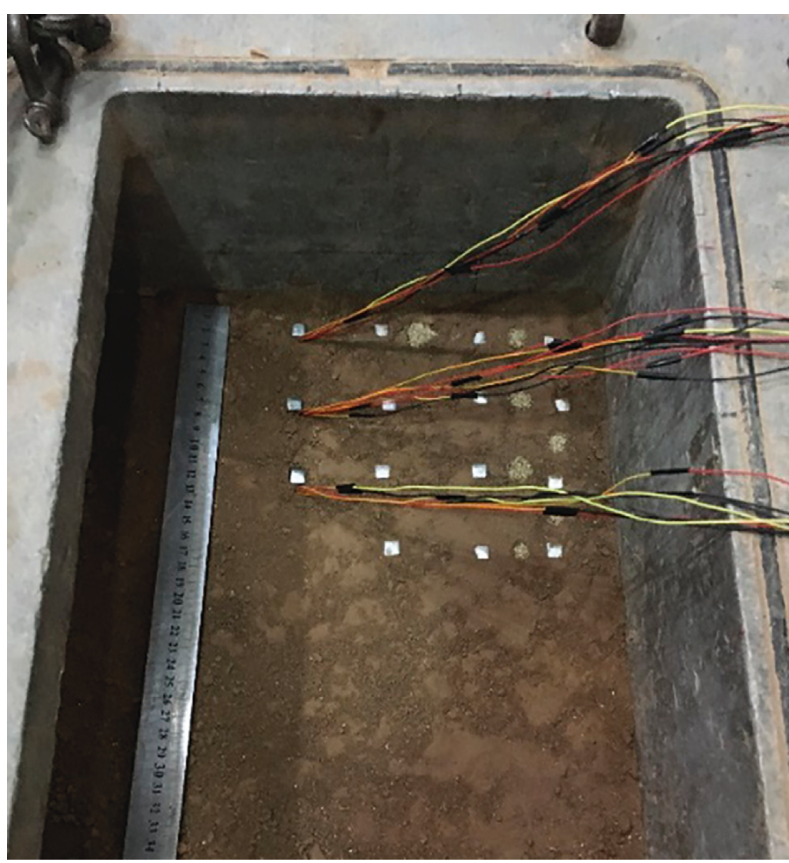

(a)

Figure 5: Composite foundation model. (a) Test model making process. (b) Model.

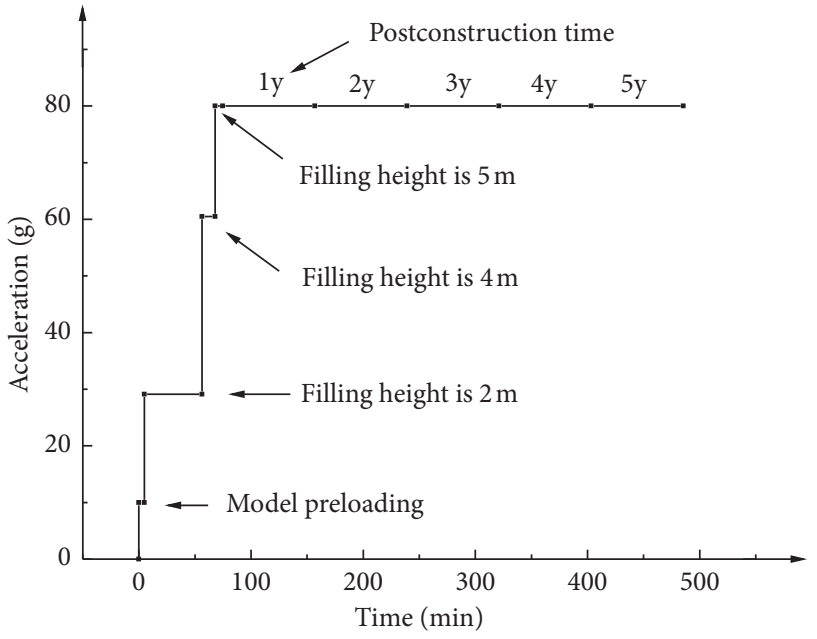

FIgURE 6: The running time curve.

the embankment filling is completed, the strength of the soil between the piles increases with time due to consolidation settlement. Therefore, the load borne by the soil between the piles gradually increases and the stress distribution of the pile and soil improves and tends to gradually become stable. As shown in Figure 9, when the roadbed filling is completed and gradually stabilized, the pile-soil stress ratio of the long pile is 2.2 times that of the short pile.

\section{Numerical Simulation}

4.1. Establishment of the Numerical Model. FLAC3D software was used to simulate the long-short pile composite

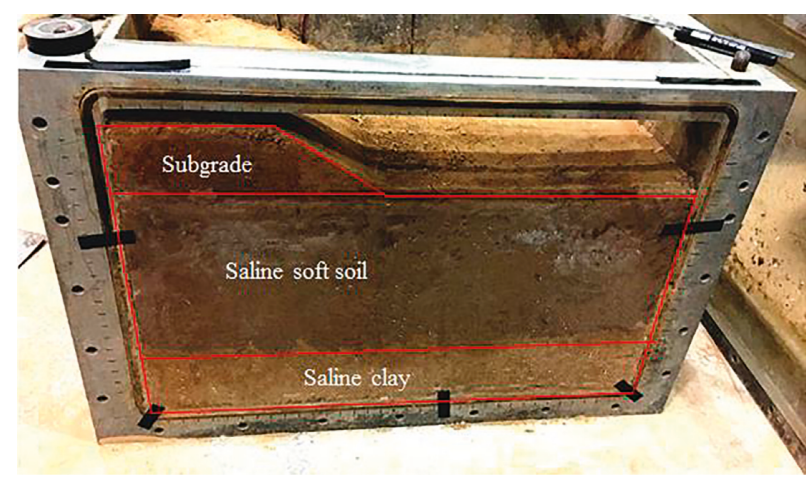

(b)

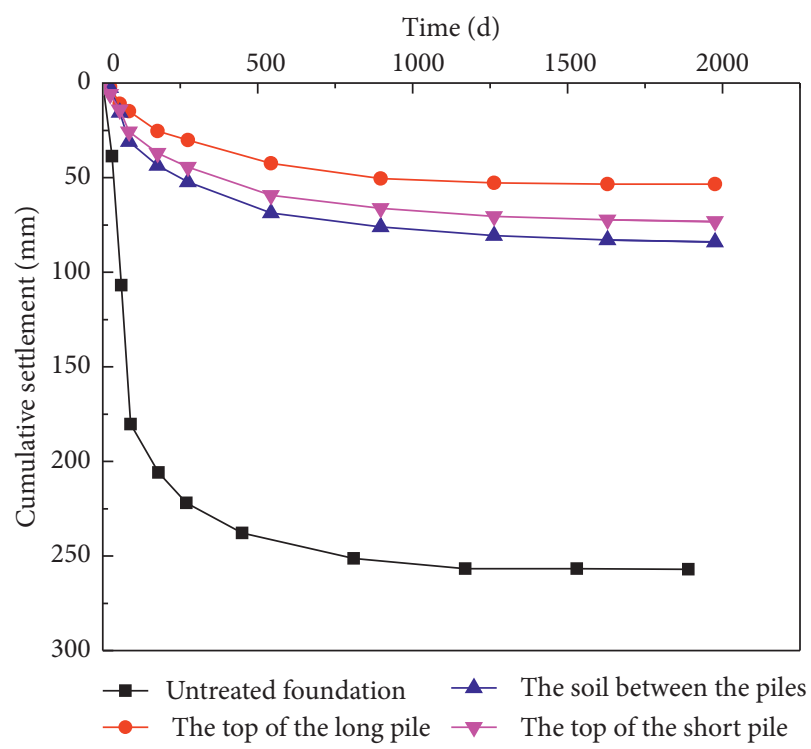

Figure 7: Cumulative settlement curves of untreated foundation and long-short pile composite foundation.

foundation. To reduce the calculation burden, half of the embankment was selected for simulation because the embankment was bilaterally symmetrical. The model (called the initial model) is shown in Figure 10. Five rows of piles were intercepted from the long-short pile composite foundation model in the direction of the route. The calculation depth and width of the model were $40 \mathrm{~m}$ and $40 \mathrm{~m}$, respectively. The length and spacing of the piles were the same as those in the field. The Drucker-Prager model was used for fill embankments, foundation soils, cushions, and gravel piles. A 


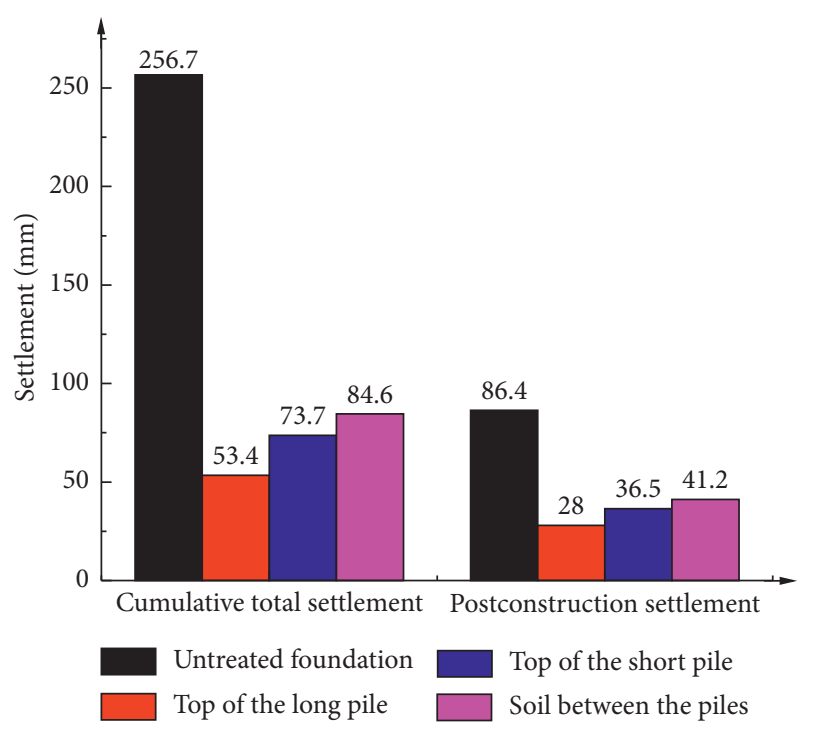

Figure 8: Total cumulative settlement and postconstruction settlement.

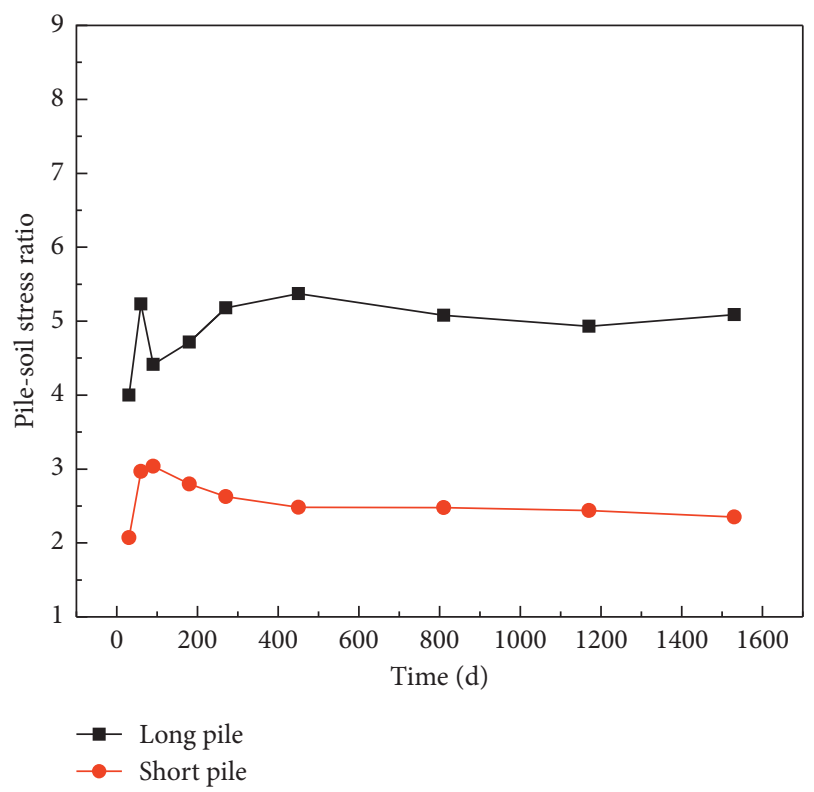

Figure 9: Curves of pile-soil stress ratio change with time.

linear elastic model was adopted for the prefabricated square pile. In addition, a contact surface was set on the pile surface to simulate the interaction between the pile and the soil.

\subsection{Boundary Condition and Material Parameter Setting.} The calculation parameters for the soil and pile were adjusted based on an engineering geological exploration report. The final parameters are shown in Tables 3 and 4 . The boundary conditions are that the left and right sides are fixed in the $x$-direction, the front and back sides are fixed in the $y$ direction, the lower surface is fixed, and the upper surface is a free boundary. The specific analysis process is as follows: before embankment loading, the initial geostress field is formed by self-balancing, then the model is activated, and the displacement stability is taken as the basis for the end of the calculation.

4.3. Comparison of Numerical Simulation and Centrifugal Test Results. Table 5 shows the results for the final settlement of the test group and the control group obtained via numerical simulation and centrifugal tests. It is evident from the table that the results of the centrifuge model tests are generally smaller than those of the numerical simulation. In the process of creating the centrifugal model, soil consolidation occurs, which increases the strength of the soil, resulting in a slightly smaller final settlement deformation. However, the settlement point recorded in the numerical simulation is close to the center of the bottom of the embankment. In the centrifuge model tests, to eliminate the influence of boundary effects, the measured settlement value is the component near the shoulder at the bottom of the embankment. Therefore, the test settlement values are slightly smaller.

Compared with the centrifuge model test, the cumulative settlement error of the numerical simulation is $2.4 \% \sim 8 \%$. The two results are in good agreement. This indicates that the parameters selected by the numerical simulation and the built composite foundation model are reasonable. Moreover, it can be further used to analyze the influencing factors of the long-short pile composite foundation.

\subsection{Factor Analysis}

4.4.1. Influence of the Replacement Rate. The replacement rate of the composite foundation is an important index in the determination of its vertical bearing capacity and affects the transmission of overlying loads and the stress and displacement fields of composite foundations [33]. However, pile spacing, pile diameter, and pile layout directly affect the replacement rate of the composite foundation. Therefore, based on numerical simulation, further modeling analysis was performed by changing the pile spacing and pile layout form. Two kinds of long and short piles arrangements were used and arranged in a square, as shown in Figure 11. In addition, according to JGJ79-2012 [32], the spacing between piles of the same pile type composite foundation is generally between 2 and 5 times the pile diameter. Therefore, $l=3 d$, $l=4 d$, and $l=5 d(d=0.5 \mathrm{~m})$, where $l$ is the spacing of the piles and $d$ is the diameter of the short piles. The modulus of the cushion is $35 \mathrm{MPa}$. The thickness of the cushion is $0.5 \mathrm{~m}$. The other parameters were the same as those of the initial model, and the specific replacement rate is shown in Table 6. In this case, the ratio of the long pile replacement rate and the short pile replacement rate corresponding to the two long and short pile arrangement forms is $1: 1$ and $1: 3$, respectively (referred to as Type $A$ and Type $B$ ), and the specific results are analyzed as follows.

It is evident from Figure 12 that there is a difference in the settlement of the pile for two different arrangements. When $l$ is equal to $5 d$, the maximum settlement of Type A long-short pile composite foundation is $7.52 \mathrm{~mm}$ less than that of the Type B long-short pile composite foundation, 


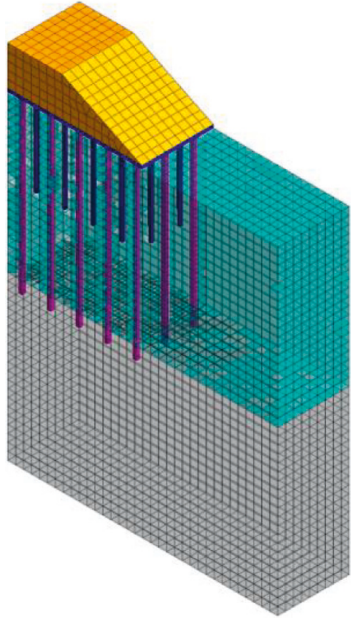

(a)

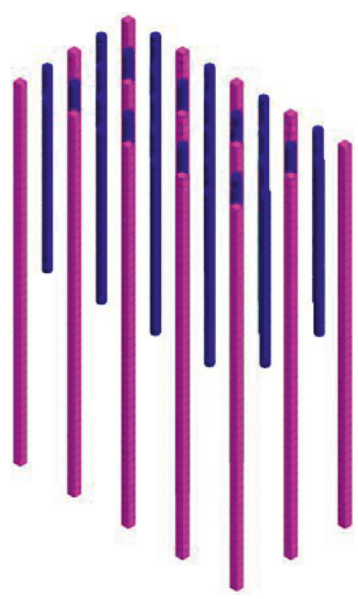

(b)

Figure 10: The initial model. (a) Foundation model. (b) Pile arrangement.

TABLE 3: Soil material parameters.

\begin{tabular}{lccccc}
\hline Name & Density $\left(\mathrm{g} / \mathrm{cm}^{3}\right)$ & Cohesion $(\mathrm{kPa})$ & Internal friction angle $\left(^{\circ}\right)$ & Poisson's ratio & Young's modulus $(\mathrm{MPa})$ \\
\hline Saline soft soil & 1.6 & 13 & 15 & 0.32 & 3 \\
Saline clay & 1.7 & 28 & 23 & 0.3 & 8 \\
Cushion & 2.1 & 5 & 30 & 0.23 & 30 \\
Subgrade & 2.1 & 15 & 27 & 0.33 & 25 \\
\hline
\end{tabular}

TABle 4: Pile material parameters.

\begin{tabular}{lccccc}
\hline Types of piles & Density $\left(\mathrm{g} / \mathrm{cm}^{3}\right)$ & Cohesion $(\mathrm{kPa})$ & Internal friction angle $\left(^{\circ}\right)$ & Poisson's ratio & Elastic modulus $(\mathrm{MPa})$ \\
\hline Long pile & 2.1 & - & - & 0.3 & $3.5 \times 10^{4}$ \\
Short pile & 2.0 & 0 & 38 & 0.25 & 70 \\
\hline
\end{tabular}

TABLE 5: Comparison of final settlement results of composite foundation.

\begin{tabular}{lcccc}
\hline & \multicolumn{2}{c}{ Control group } & \multicolumn{3}{c}{ Test group } \\
Name & Untreated foundation & \multicolumn{2}{c}{ Long-short pile composite foundation } \\
& Foundation settlement $(\mathrm{mm})$ & Soil between piles $(\mathrm{mm})$ & Top of long pile (mm) & Top of short pile (mm) \\
\hline Numerical simulation & 272.1 & 91.4 & 54.7 & 78.7 \\
Centrifuge model test & 256.7 & 84.6 & 53.4 & 73.7 \\
\hline
\end{tabular}

which is approximately $9.1 \%$. When $l$ is equal to $4 d$, the corresponding maximum settlement is reduced by $3.69 \mathrm{~mm}$, which represents a reduction of approximately 5\%. In addition, when $l$ is equal to $3 d$, the corresponding maximum settlement is only reduced by $1.71 \mathrm{~mm}$, which represents a reduction of approximately $2.5 \%$. Therefore, when the pile spacing is constant, the influence of different long and short pile arrangements (Type A and Type B) on the settlement is relatively limited. However, under the same long and short pile arrangement, the change pile spacing has a greater influence on the settlement of the composite foundation. For Type $\mathrm{B}$, when the pile spacing is changed from $5 d$ to $4 d$ and $3 d$, the maximum settlement of the foundation decreased by $10.3 \%$ and $15.5 \%$, respectively. The maximum settlement corresponding to Type A decreased by $6.2 \%$ and $9.3 \%$, respectively. It is evident that the influence of the pile spacing on the settlement of the composite foundation is greater than that of the arrangement. Compared to the pile spacing between $4 d$ and $5 d$, when the spacing is between $3 d$ and $4 d$, the variation of the settlement for the two models is relatively small.

Comparing the settlement changes of the long piles for the two arrangements, it is evident that the settlement variation of the long piles is small when the pile spacing is between $3 d$ and $4 d$. This shows that the effect of controlling the settlement by reducing the pile spacing is not obvious under these conditions. Moreover, a reduction of the pile spacing increases the number of piles, resulting in wastage. When the pile spacing is between $4 d$ and $5 d$, the settlement change of the long pile is obviously larger than that of the former, so it is more reasonable to adopt the pile spacing of $4 d \sim 5 d$. 


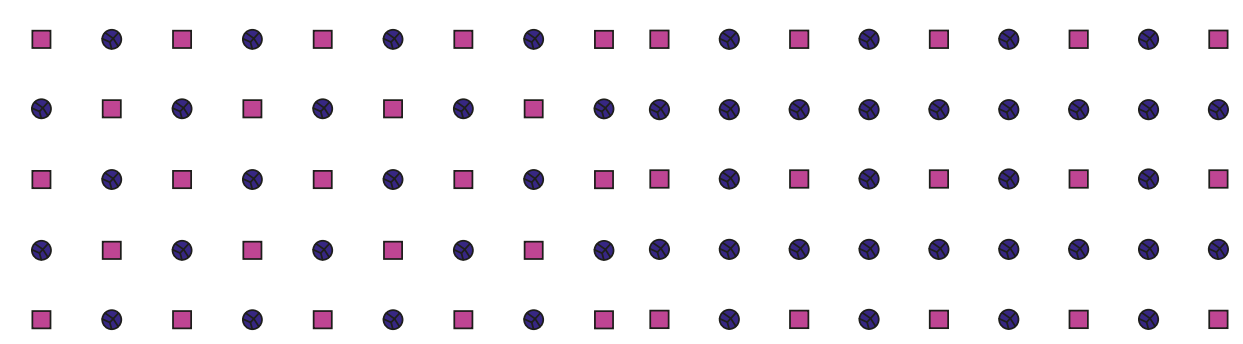

(a)

(b)

FIgURE 11: Long and short pile arrangement. (a) A. (b) B.

TABLE 6: Replacement ratios corresponding to different arrangements.

\begin{tabular}{|c|c|c|c|c|}
\hline \multirow{2}{*}{$l$} & \multicolumn{2}{|c|}{ A } & \multicolumn{2}{|c|}{ B } \\
\hline & Long pile & Short pile & Long pile & Short pile \\
\hline $3 d$ & 0.044 & 0.044 & 0.022 & 0.065 \\
\hline $4 d$ & 0.025 & 0.025 & 0.012 & 0.036 \\
\hline $5 d$ & 0.016 & 0.016 & 0.008 & 0.024 \\
\hline
\end{tabular}

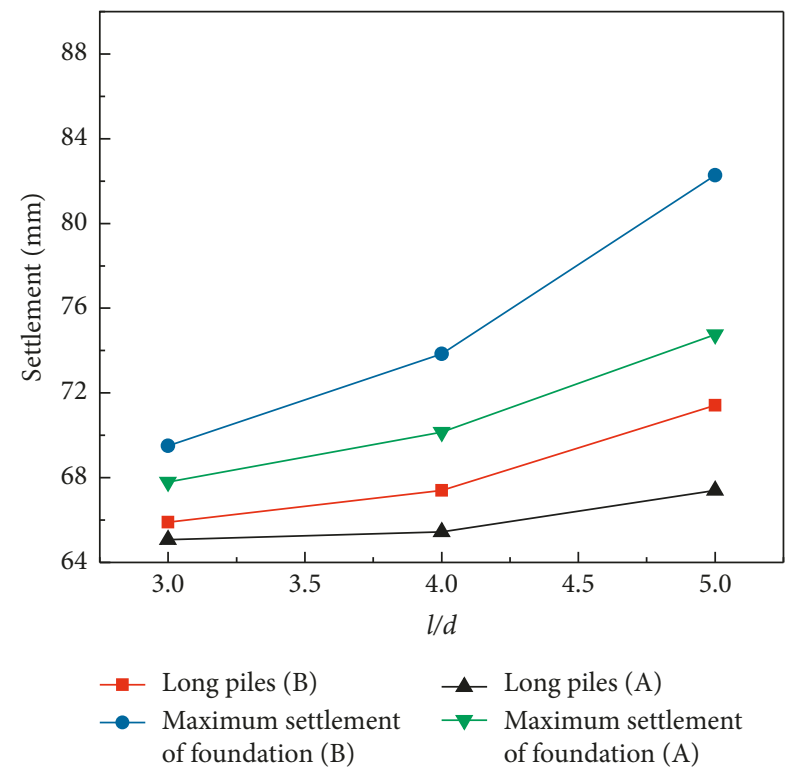

FIGURE 12: Influence of layout and pile spacing on the settlement of long-short pile composite foundation.

It is evident from Figure 13 that the stress state and variation law of long pile, short pile, and the soil between the piles are close for the two kinds of long and short pile arrangements. When the pile spacing is the same, the stress and stress ratio of the long pile, short pile, and the soil between the piles for Type B are larger than those for Type A, but the difference is small. With the increase of the pile spacing, the stress on top of the long pile and the pile-soil stress ratio for the two arrangements clearly increase. This indicates that the pile spacing has a greater influence on the stress acting on the long and short piles and the soil between the piles, compared to the layout. Furthermore, the reduction of the pile spacing increases the replacement rate of the piles, but this is not conducive to the effective exploitation of the bearing capacity of long piles. On the contrary, it increases the cost. When the pile spacing increases from $4 d$ to $5 d$, the stress on top of the long pile increases rapidly, indicating that the bearing capacity of the long pile is more effectively utilized. Therefore, it is more reasonable to use a pile spacing of $4 d \sim 5 d$.

It is evident from Figure 13 that although the stress at the top of the short pile and the pile-soil stress ratio is gradually increased, the change is small and the short pile stress is approximately $1 / 4$ of the long pile stress. When the pile spacing changes, the ratio changes slightly. However, with the increase of the pile spacing, the stress difference between the two increases. The stress on the soil between the piles increases slightly with a decrease of the pile spacing, but the effect is small. It is evident that the reduction of the pile spacing is not only beneficial to the bearing of the soil between the piles but also to the overall bearing of the soil between the piles. Figures 12 and 13 show that as the pile spacing increases, the pile-soil stress ratio of the long and short piles gradually increases, and the long piles bear a large component of the load. Therefore, the settlement of the long piles is larger. The settlement of the long-short pile composite foundation is mainly controlled by the long piles.

4.4.2. Effect of Pile Length. To investigate the influence of pile length on the settlement and stress state of the composite foundation, the length of the long pile was set as $16 \mathrm{~m}$, $18 \mathrm{~m}, 20 \mathrm{~m}, 22 \mathrm{~m}$, and $24 \mathrm{~m}$, respectively. The ratio of the length of the short pile to the length of the long pile (referred to as the pile length ratio) is $0.3,0.4,0.5,0.6$, and 0.7 , respectively. The other parameters are the same as those of the initial model for the numerical simulations. The specific results are shown in Figures 14 and 15.

Figure 14(a) shows that the settlement of the composite foundation can be effectively controlled by changing the length of the pile. When the pile length ratio is determined, as the length of the long pile increases, the length of the short pile also increases correspondingly, and the settlement of the composite foundation decreases at a larger rate. When the 


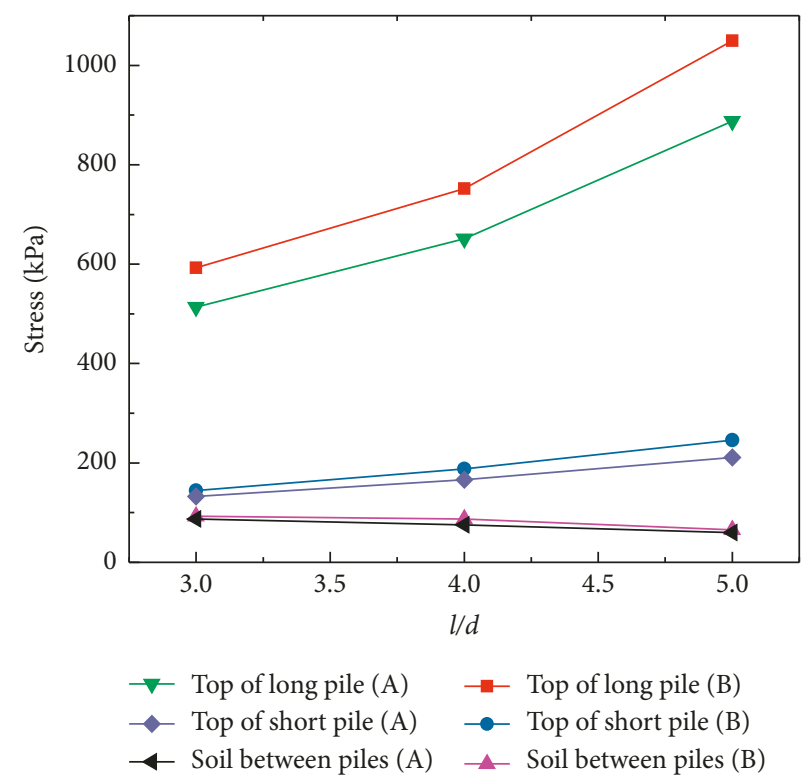

(a)

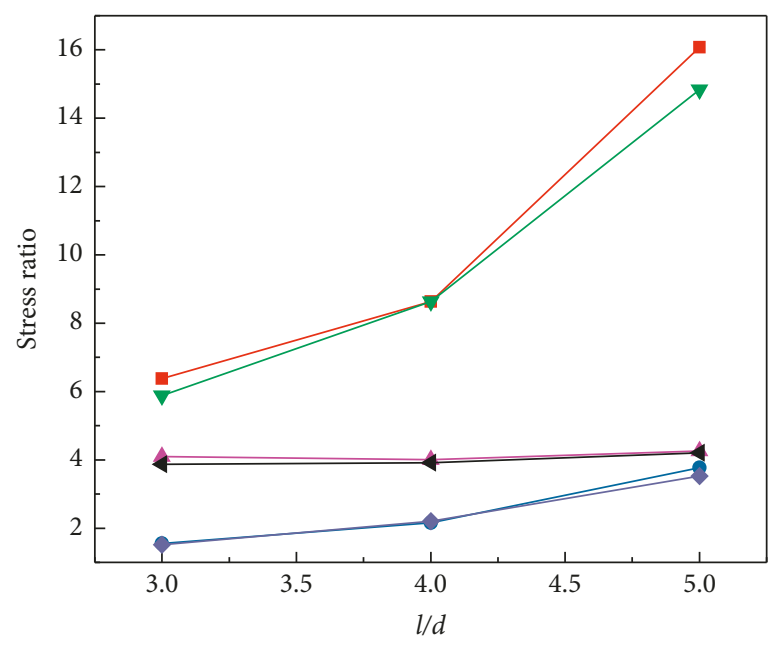

$\neg$ Pile-soil stress ratio of long pile (A)
- Pile-soil stress ratio of short pile (A)
$\leftarrow$ Long pile/short pile (A)
- Pile-soil stress ratio of long pile (B)
- Pile-soil stress ratio of short pile (B)
- Long pile/short pile (B)

(b)

FIGURE 13: Effect of arrangement and pile spacing on bearing capacity of long-short pile composite foundation. (a) Stress. (b) Stress ratio.

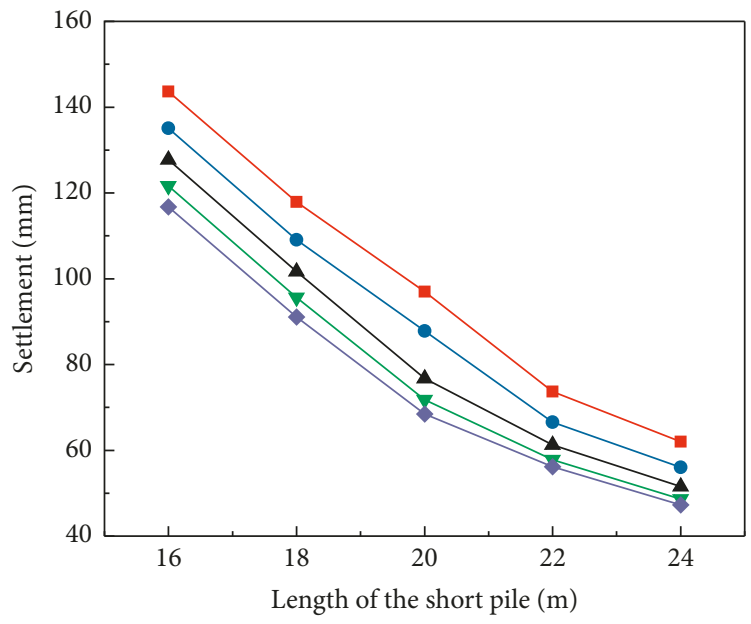

Pile length ratio

$\begin{array}{ll}\rightarrow 0.3 & \rightarrow 00 \\ \longrightarrow 0.4 & \longrightarrow 0.7\end{array}$

(a)

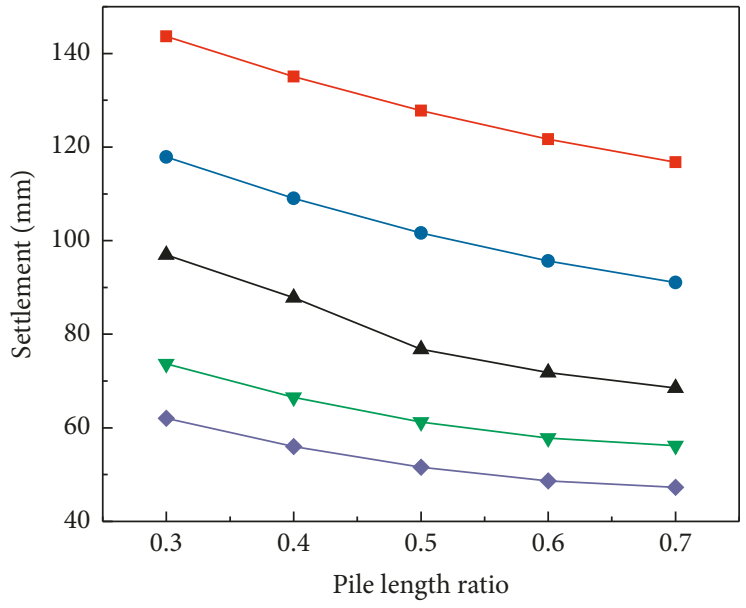

The length of the long pile

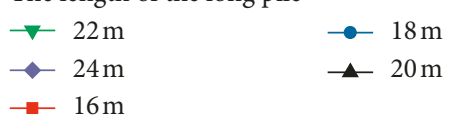

(b)

FIGURE 14: Influence of pile length on settlement of composite foundation. (a) Variation of length of long piles. (b) Variation of pile length ratio.

length of the long pile increases from $16 \mathrm{~m}$ to $24 \mathrm{~m}$, the maximum reduction of the composite foundation settlement is $56.9 \%$. However, when the length of the long pile exceeds $22 \mathrm{~m}$, the settlement rate of the composite foundation is significantly reduced. This shows that after the long pile reaches the bearing stratum, the influence of increasing the pile length on the settlement of the composite foundation is reduced. It is evident from Figure 14(b) that when the length of the long pile is determined, as the pile length ratio increases (i.e., the length of the short pile increases), the settlement of the composite foundation also gradually decreases; however, the rate of reduction is less than that of the 


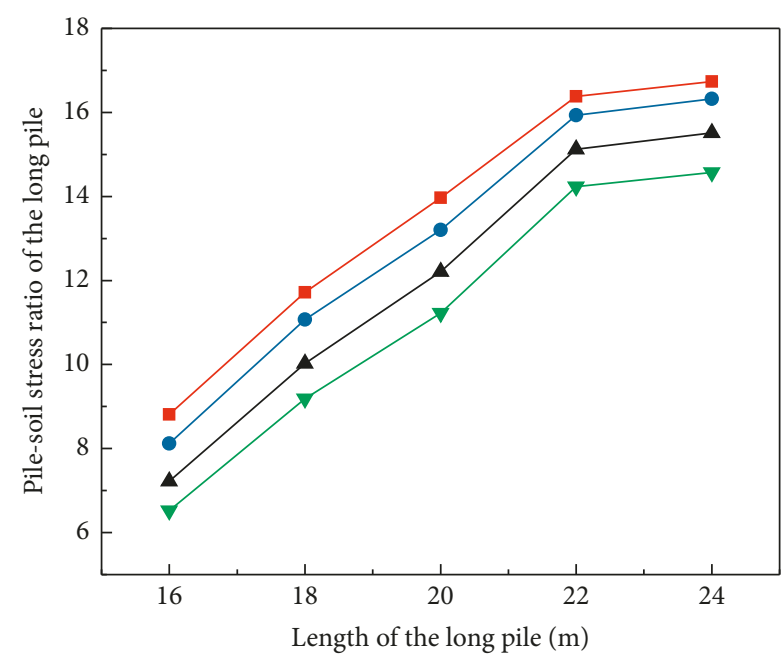

Pile length ratio

$\rightarrow 0.4 \quad-0.6$

FIGURE 15: Influence of pile length on long pile stress.

former (caused by the change of the length of long piles). If the long pile does not reach the bearing layer, the effect of reducing the settlement is obvious. When the length of the long pile is $22 \mathrm{~m}$, the influence of the increase of the length of the short pile on the settlement is less significant. When the pile length ratio is 0.6 , the effect disappears. Therefore, when the long pile reaches the bearing stratum, the length of the short pile should not exceed 0.6 times the length of the long pile to avoid wastage of the pile.

Figure 15 shows that when the pile length ratio is determined, the pile-soil stress ratio of the long pile increases linearly with the increase of the length of the long pile. When the long pile $(22 \mathrm{~m})$ reaches the bearing layer, the growth rate of the pile-soil stress ratio slows down significantly. Even if its length is increased to $24 \mathrm{~m}$, the change of its stress state is no longer significant. However, when the length of the long pile is constant, the increase of the pile length ratio reduces the pile-soil stress ratio of the long pile. This shows that the increase of the length of the short pile increases the load that it bears.

4.4.3. Influence of Cushion. The gravel cushion plays an important role in improving the bearing capacity of the foundation, ensuring that the pile and the soil body act as a whole to bear the force together and adjusting the load sharing ratio of the pile and soil [34]. To study the influence of the cushion on the settlement characteristics and bearing capacity of the long-short pile composite foundation, numerical simulations were conducted. For $l=4 d$ and Type B, the elastic modulus of the cushion layer was $35 \mathrm{MPa}, 50 \mathrm{MPa}$, $70 \mathrm{MPa}, 90 \mathrm{MPa}, 110 \mathrm{MPa}$, and $140 \mathrm{MPa}$, respectively, and other parameters were the same as those of the initial model. The results obtained were analyzed as follows.

As is evident from Figure 16, the setting cushion has an obvious effect on the reduction of foundation settlement.

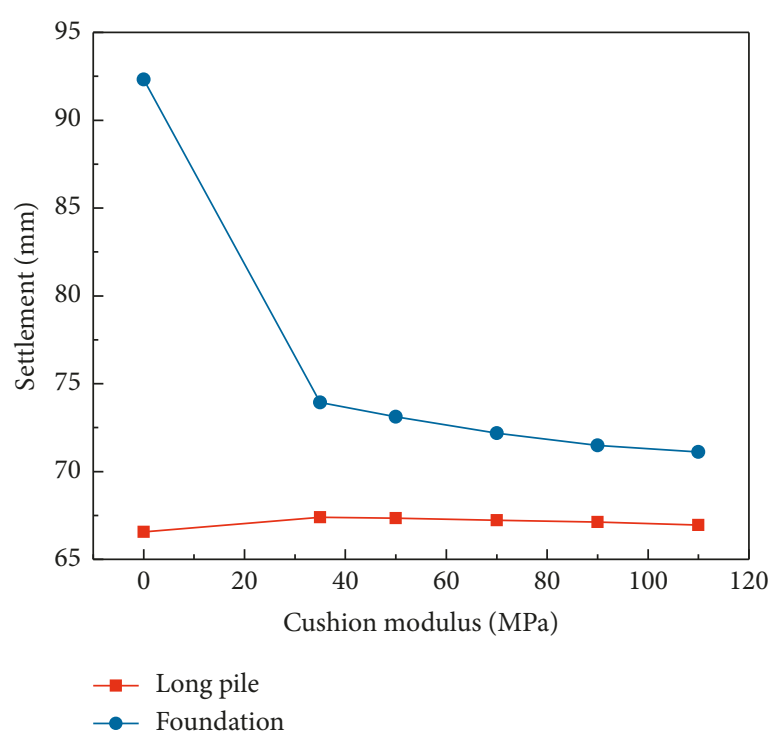

FIGURE 16: Effect of cushion on the settlement of long-short pile composite foundation.

Compared to the foundation without cushion, the maximum settlement of the foundation with cushion with a modulus of elasticity of $35 \mathrm{MPa}$ is reduced from $92.3 \mathrm{~mm}$ to $73.9 \mathrm{~mm}$, which represents a reduction by $20 \%$. In addition, the settlement of the long pile increases from $66.6 \mathrm{~mm}$ to $67.4 \mathrm{~mm}$ and the corresponding uneven settlement decreases from $25.7 \mathrm{~mm}$ to $6.5 \mathrm{~mm}$, which represents a decrease of $74.7 \%$. This shows that setting the cushion not only reduces the uneven settlement of the composite foundation but also facilitates the bearing of the pile and the soil between the piles. When the modulus of elasticity of the cushion increases from $35 \mathrm{MPa}$ to $140 \mathrm{MPa}$, the settlement of the foundation decreases further and the corresponding settlement difference decreases to $4.1 \mathrm{~mm}$.

The effect of the cushion on the bearing characteristics of the long-short pile composite foundation is shown in Figure 17. The setting of the cushion significantly increases the stress on the long pile. The stress on top of the pile increases from $291.9 \mathrm{kPa}$ to $740.2 \mathrm{kPa}$ and the corresponding pile-soil stress ratio increases from 3.4 to 10.0. This shows that the bearing advantages of long piles are not fully developed before the cushion is set up. This explains the reason why the settlement of long piles increases in the case of setting the cushion. With the increase of the cushion modulus, the stress on the long piles increases linearly, but the growth rate is slower. When the cushion modulus is $110 \mathrm{MPa}$, the stress ratio is 5.3. Unlike the long piles, the stress on the short piles decreases significantly after the cushion is placed. The stress on top of the pile decreases from $334.9 \mathrm{kPa}$ to $187.7 \mathrm{kPa}$ and the corresponding stress ratio of the pile to the soil decreases from 3.9 to 2.5 . When the modulus of the cushion gradually increases from $35 \mathrm{MPa}$ to $110 \mathrm{MPa}$, the stress on the short pile and the pile-soil stress ratio first increases slightly and then slowly decreases. In addition, the pile-soil stress ratio is basically stable between 2.7 and 2.3. As the cushion modulus increases, the stress ratio of the long and short piles gradually 


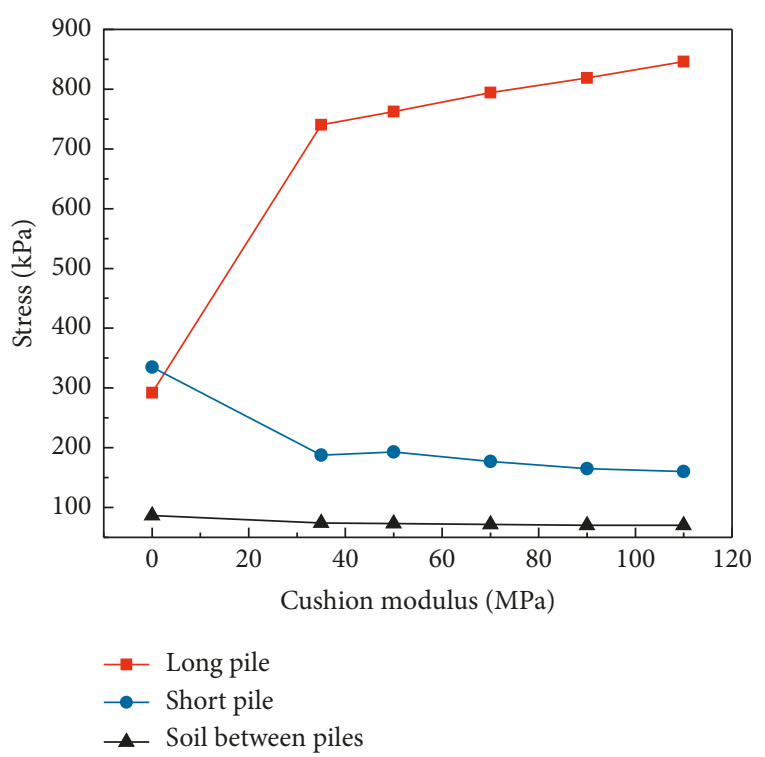

(a)

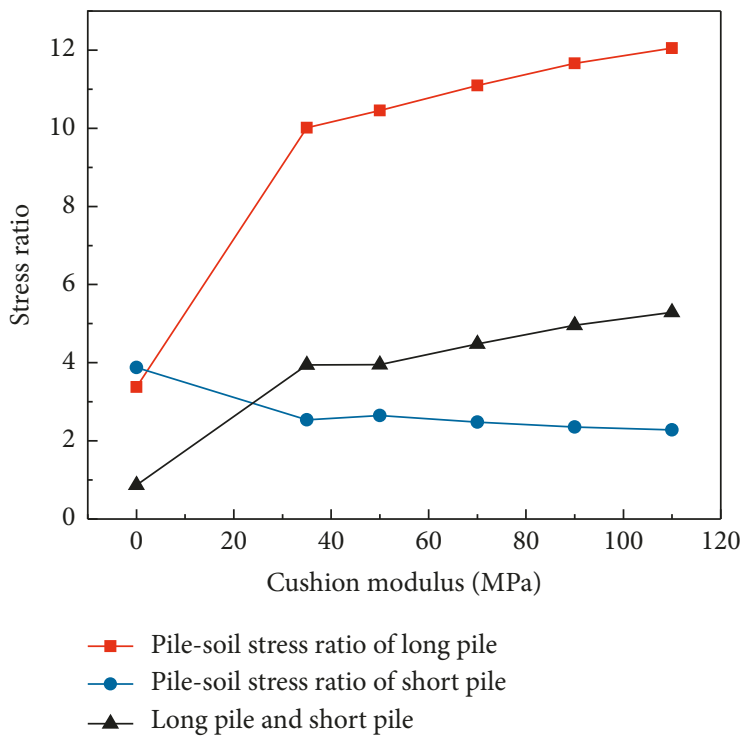

(b)

FIGURE 17: Effect of cushion on bearing characteristics of long-short pile composite foundation. (a) Variation of stress. (b) Variation of stress ratio.

increases from 0.9 to 5.3. The stress on the soil between the piles is always at a low level with or without the cushion. However, after setting the cushion, the stress on the soil between the piles tend to decrease slightly.

In this study, the change rule of the stress on the long pile with the elastic modulus of cushion is consistent with that of Liang et al. [16], while the change rule of short pile is slightly different from it. This may be due to the different types of piles and soils selected. Besides the modulus of the cushion, the thickness of the cushion may have an important influence on the behavior of the composite foundation. There are more studies on the influence of cushion thickness $[16,17]$. So, this study is aimed at cushion with different elastic moduli. In a word, when choosing a cushion of a longshort pile composite foundation, the influence of modulus and thickness should be considered.

\section{Conclusions}

To study the deformation characteristics of a long-short pile composite foundation in saline soft soil region and to analyze its influencing factors, indoor centrifuge model tests were conducted as part of this investigation. The settlement and the variation of the pile-soil stress ratio for a long-short pile composite foundation were analyzed. In addition, numerical simulation under the same working condition was performed. On the basis of verifying the rationality and reliability of the numerical simulation model, the influencing factors of the long-short pile composite foundation were systematically studied. The main conclusions are as follows:

(1) Long and short piles can effectively control the settlement of a saline soft soil foundation. Compared with the untreated foundation, the total settlement of the long-short pile composite foundation was reduced by $67 \%$, and the postconstruction settlement was reduced by $47.7 \%$. In addition, postconstruction settlement of long-short pile composite foundation accounted for a relatively large proportion, approximately 0.5 times the total accumulated settlement. When the pile-soil stress of the long and short piles was stable, the pile-soil stress ratio of the long piles was 2.2 times that of the short piles. The results of numerical simulations were in good agreement with those of the centrifuge model tests, and the error of the numerical simulations for the settlement analysis was between $2.4 \%$ and $8 \%$. Therefore, the rationality and reliability of the numerical simulation and associated parameters were verified, which can be further used to analyze the influencing factors of the deformation characteristics of the long-short pile composite foundation.

(2) The influence of pile spacing on the settlement of the long-short pile composite foundation was greater than that caused by the arrangement of the piles. Under this geological condition, it is reasonable to choose a pile spacing of $4 d \sim 5 d$. With the increase of the pile spacing, the stress on the piles and the pile-soil stress ratio on the long and short piles exhibited an increasing trend for the two arrangements. Moreover, the short pile stress was approximately $1 / 4$ of the long pile stress. When the long pile reaches the bearing stratum, the length of the short pile should not exceed 0.6 times that of the long pile. The cushion had an obvious effect on the reduction of the settlement of the composite foundation with long and short piles. This is beneficial to the joint bearing capacity of the pile and the soil between the piles. Compared to the foundation without cushion, the maximum settlement of a foundation with cushion with a modulus of elasticity of $35 \mathrm{MPa}$ was reduced from $92.3 \mathrm{~mm}$ to $73.9 \mathrm{~mm}$, which represents a reduction by $20 \%$. When 
the cushion modulus increases from $35 \mathrm{MPa}$ to $110 \mathrm{MPa}$, the stress of the long pile and its pile-soil stress ratio increase linearly at a slower rate while the stress of the short pile and its pile-soil stress ratio increase slightly at first followed by a gradual decrease.

(3) In this report, the settlement characteristics of a longshort pile composite foundation and its influencing factors were analyzed using an indoor centrifugal test and numerical simulations. The results can provide a reference for the associated high-speed railway project and related projects. However, as a new foundation treatment method, the different pile spacings of long and short piles have a great influence on the test results. In this paper, the numerical simulations of the spacing between the piles of $3 d, 4 d$, and $5 d$ were carried out. This is incomplete and has some limitations. In addition, the influence of corrosion characteristics is considered only when selecting the type of long and short piles. This influence on the settlement and stress characteristics of a long-short pile composite foundation has not been studied in detail and therefore should be investigated in the future.

\section{Data Availability}

The data used to support the findings of this study are available from the corresponding author upon request.

\section{Conflicts of Interest}

The authors declare that there are no conflicts of interest.

\section{Acknowledgments}

This research was supported by the Natural Science Foundation of China (Grant no. 51209006), the Major Scientific Research Project of the China Railway Group (Grant no. 2017-major-11-04), and the Fundamental Research Funds for the Central Universities, CHD (Grant no. 300102219219).

\section{References}

[1] S. Zhang, Y. Wang, F. Xiao, and W. Chen, "Large-scale model testing of high-speed railway subgrade under freeze-thaw and precipitation conditions," Advances in Civil Engineering, vol. 2019, Article ID 4245916, 14 pages, 2019.

[2] Y. Lv, H. Liu, X. Ding, and G. Kong, "Field tests on bearing characteristics of $\mathrm{X}$-section pile composite foundation," Journal of Performance of Constructed Facilities, vol. 26, no. 2, pp. 180-189, 2012.

[3] M. Yang, "Study on reducing-settlement pile foundation based on controlling settlement principle," Chinese Journal of Geotechnical Engineering, vol. 22, no. 4, pp. 482-486, 2000.

[4] C. D. F. Rogers and S. Glendinning, "Improvement of clay soils in situ using lime piles in the UK," Engineering Geology, vol. 47, no. 3, pp. 243-257, 1997.

[5] X. T. Xu, H. L. Liu, and B. M. Lehane, "Pipe pile installation effects in soft clay," Proceedings of the Institution of Civil Engineers-Geotechnical Engineering, vol. 159, no. 4, pp. 285296, 2006.
[6] S. S. Chandrasekaran, A. Boominathan, and G. R. Dodagoudar, "Group interaction effects on laterally loaded piles in clay," Journal of Geotechnical and Geoenvironmental Engineering, vol. 136, no. 4, pp. 573-582, 2010.

[7] H.-L. Liu, J. Chu, and A. Deng, "Use of large-diameter, cast-in situ concrete pipe piles for embankment over soft clay," Canadian Geotechnical Journal, vol. 46, no. 8, pp. 915-927, 2009.

[8] F. Y. Liu, M. I. Wei, and L. Zhang, "Experimental study of the electro-osmosis consolidation of soft clay under anode followup," Journal of Civil Architectural \& Environmental Engineering, vol. 3, no. 3, pp. 188-197, 2014.

[9] J. Yuan and M. A. Hicks, "Numerical simulation of elastoplastic electro-osmosis consolidation at large strain," Acta Geotechnica, vol. 11, no. 1, pp. 127-143, 2016.

[10] S. Gledinning, J. Lamont-Black, C. J. F. P. Jones, and J. Hall, "Treatment of lagoooned sewage sludge in situ using electrokinetic geosynthetics," Gcosynthetics International, vol. 15, no. 3, pp. 192-204, 2008.

[11] H. M. Yue, J. M. Huang, T. Wen, and H. Z. Mi, "Experimental study of foundation treatment of sulphate saline sandy soil using heavy cover replacement technique," Rock and Soil Mechanics, vol. 38, no. 2, pp. 471-486, 2017.

[12] Y. Zhang, J. H. Fang, J. K. Liu, and A. H. Xu, "Field tests on reinforcement effects of ground treatment of composite foundation in saline soils by dynamic compaction replacement," Chinese Journal of Geotechnical Engineering, vol. 33, no. 1, pp. 251-254, 2011.

[13] Y. G. Chen, J. Yang, Z. P. Peng, Z. Y. Lian, and L. Tao, “Test analysis on pore water pressure in ground treatment to saturated saline soil," Chinese Journal of Geotechnical Engineering, vol. 32, no. S2, pp. 529-532, 2010.

[14] Z. P. Peng, J. Yang, Y. G. Chen, and Z. Y. Lian, "Experimental study on ground improvement of saturated saline soil with dynamic consolidation and drainage stone columns," Chinese Journal of Geotechnical Engineering, vol. 32, no. S2, pp. 136-141, 2010.

[15] Y. D. Wu, C. H. Shi, J. Liu, and Z. G. Li, "Study on the bearing characteristics of long-short piles composite foundation under embankment load," Forensic Engineering, vol. 12, pp. 673-681, 2012.

[16] F.-Y. Liang, L.-Z. Chen, and X.-G. Shi, "Numerical analysis of composite piled raft with cushion subjected to vertical load," Computers and Geotechnics, vol. 30, no. 6, pp. 443-453, 2003.

[17] J.-J. Zheng, S. W. Abusharar, and X.-Z. Wang, "Three-dimensional nonlinear finite element modeling of composite foundation formed by CFG-lime piles," Computers and Geotechnics, vol. 35, no. 4, pp. 637-643, 2008.

[18] X.-Z. Wang, J.-J. Zheng, and J.-H. Yin, "On composite foundation with different vertical reinforcing elements under vertical loading: a physical model testing study," Journal of Zhejiang University SCIENCE A, vol. 11, no. 2, pp. 80-87, 2010.

[19] M. Samanta and R. Bhowmik, "3D numerical analysis of piled raft foundation in stone column improved soft soil," International Journal of Geotechnical Engineering, vol. 13, no. 5, pp. 474-483, 2019.

[20] M. Samanta and R. Bhowmik, "Numerical analysis of piledraft foundation under vertical load in stone column improved soil," in Proceedings of the Indian Geotechnical Conference, Roorkee, India, December 2013.

[21] M. H. Zhao, L. Zhang, and M. H. Yang, "Settlement calculation for long-short composite piled raft foundation," Journal 
of Central South University of Technology, vol. 13, no. 6, pp. 749-754, 2006.

[22] Y. Lou, N. He, and B. Lou, "Analysis of soil arching of composite foundations with long and short piles," Chinese Journal of Geotechnical Engineering, vol. 33, no. 1, pp. 77-80, 2011.

[23] B. Li, M. S. Huang, Y. Cheng, G. B. Ye, and P. L. Xiang, "Filed test and numerical analysis of composite foundation with long and short piles under embankment," China Journal of Highway and Transport, vol. 26, no. 1, pp. 9-14, 2013.

[24] Z. Q. Lin, W. D. Huang, Y. B. Jiang, and G. R. Zhong, "Analysis and precautionary measures of engineering accidents of composite foundations with long and short piles," Chinese Journal of Geotechnical Engineering, vol. 39, no. 1, pp. 185-191, 2017.

[25] T. Z. Ma, Y. P. Zhu, Y. Z. Ren, and Y. Q. Ling, "Bearing capacity and displacement characteristics of long-short composite piles in loess areas," Chinese Journal of Geotechnical Engineering, vol. 40, no. 1, pp. 259-265, 2018.

[26] S. Z. Li, X. N. Ma, and Z. B. Tian, "Experimental study on long-short piles reinforced loess foundation for high speed railway," Journal of the China Railway Society, vol. 38, no. 10, pp. 78-84, 2016.

[27] Y. P. Zhu, X. H. Yang, T. Z. Ma, and A. M. Li, "Bearing behavior and optimization design of large-diameter long pile foundation in loess subsoil," Chinese Journal of Rock Mechanics and Engineering, vol. 36, no. 4, pp. 1012-1023, 2017.

[28] S. Z. Li, X. N. Ma, and Z. B. Tian, "Research on influence factors of long-short pile reinforced loess foundation under embankment," Journal of Railway Science and Engineering, vol. 14, no. 2, pp. 241-249, 2017.

[29] J. Sharma and M. D. Bolton, "Centrifugal and numerical modelling of reinforced embankments on soft clay installed with wick drains," Geotextiles and Geomembranes, vol. 19, no. 1, pp. 23-44, 2001.

[30] S. Springman, M. Bolton, J. Sharma, and S. Balachandran, "Modelling and instrumentation of a geotextile in the geotechnical centrifuge," in Proceedings of the International Symposium on Earth Reinforcement Practice, pp. 167-172, Fukuoka, Japan, November 1992.

[31] X. G. Wu, X. S. Dai, K. N. Zhang, Y. Liu, and C. Ling, "Study on centrifugal model test of rigid pile foundation," Journal of Civil Engineering and Management, vol. 35, no. 5, pp. 13-21, 2018.

[32] JGJ79-2012, National Standard of the People's Republic of China, Technical Code for Ground Treatment of Buildings, China Architecture \& Building Press, Beijing, China, 2012.

[33] L. X. Li, J. J. Huang, X. Y. Cheng, F. Hu, and Q. H. Fu, "Centrifuge model tests on the interaction between rigid-pile composite foundation in the vicinity of a deep excavation and its retaining structure," Chinese Journal of Rock Mechanics and Engineering, vol. 36, no. 2, pp. 4142-4150, 2017.

[34] J. T. Shahu, M. R. Madhav, and S. Hayashi, "Analysis of soft groundgranular pile-granular mat system," Computers and Geotechnics, vol. 27, no. 1, pp. 45-62, 2001. 


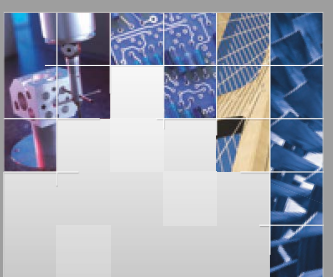

\section{Enfincering}
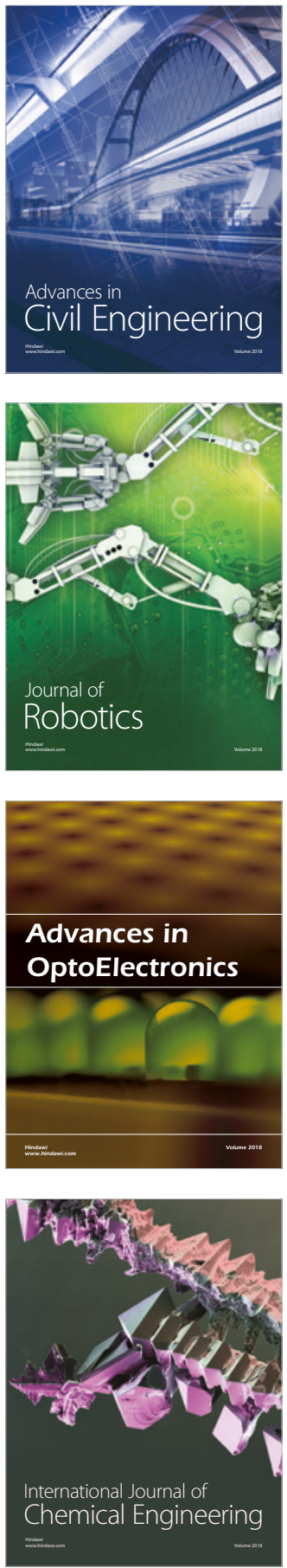

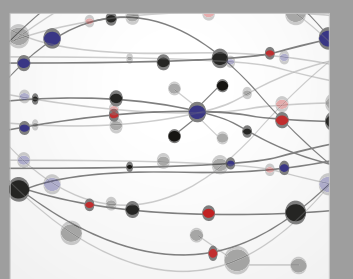

\section{Rotating \\ Machinery}

The Scientific World Journal

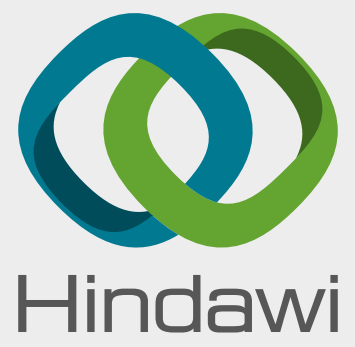

Submit your manuscripts at

www.hindawi.com
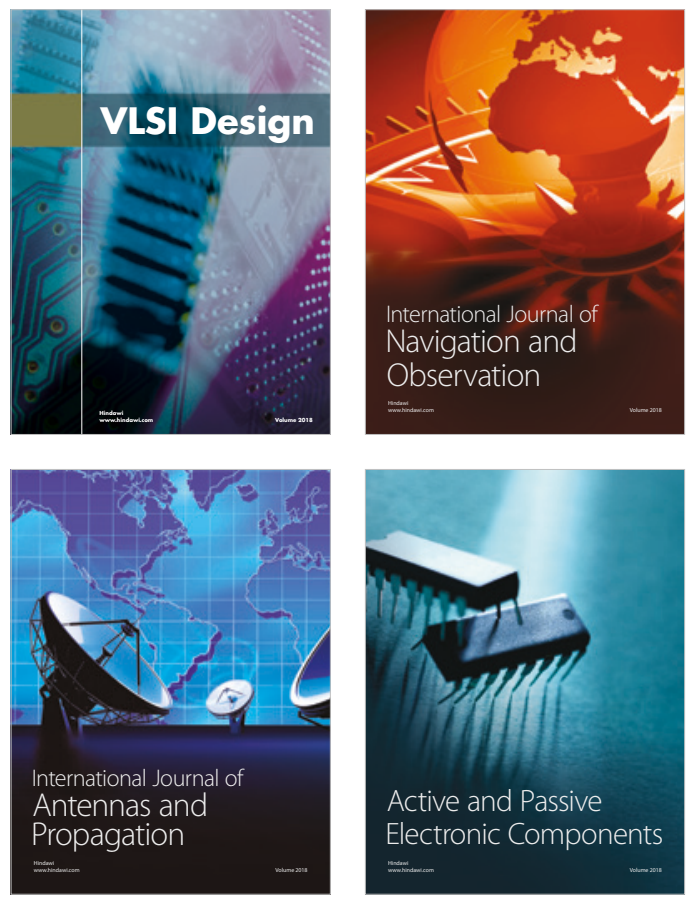
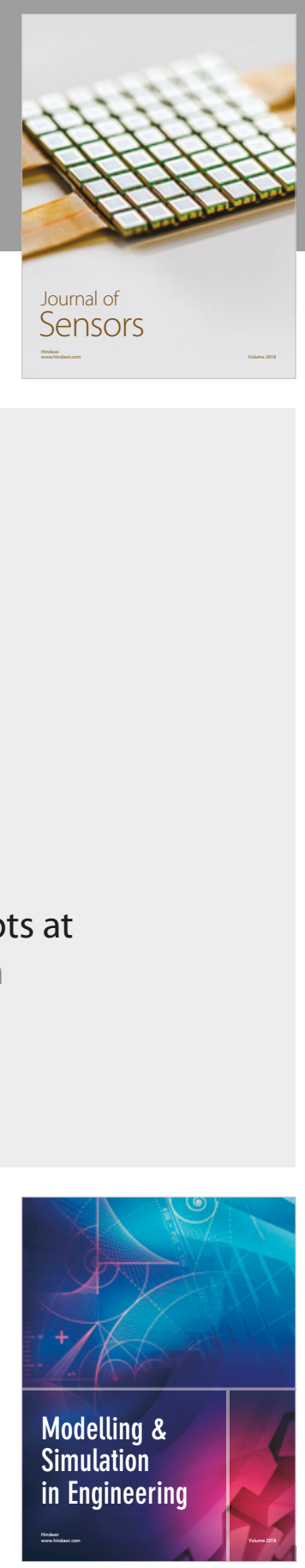

\section{Advances \\ Multimedia}
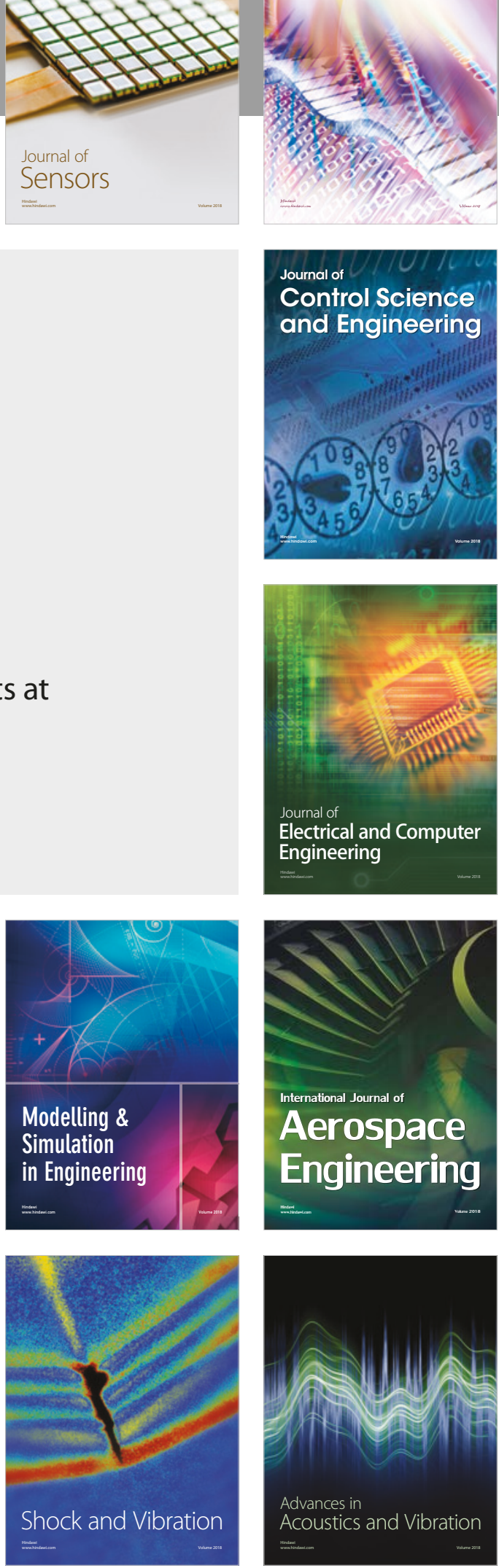